\title{
Construcción COLECTIVA de la CIUDAD. Tenencia de la TIERRA Y REgENERACIÓN URBANA EN LOS ASENTAMIENTOS INFORMALES de Maputo, Mozambique
}

Colective Construction of the City. Land Tenure and Urban Renewal in the Informal Settlements of Maputo, Mozambique

\author{
Ana Cubillo Arias \\ ana.cubillo.arias@mail.com \\ Arquitectura Sin Fronteras - España
}

RESUMEN: Los barrios informales de Maputo, capital de Mozambique, albergan al $80 \%$ de una población urbana muy pobre, con altas densidades de ocupación y altos niveles de precariedad del hábitat. Maputo, como las demás ciudades africanas se enfrenta al reto de cómo hacer frente al crecimiento de la población urbana previsto y simultáneamente mejorar las condiciones de vida precarias en los asentamientos informales garantizando el derecho a la ciudad para todos los habitantes sin generar lógicas de crecimiento urbano poco sostenibles desde el punto de vista medio ambiental y social. Estos barrios no pueden ser mejorados únicamente a través de grandes operaciones de planeamiento urbano o de intervención en infraestructuras estructurantes. La propuesta de Arquitectura Sin Fronteras-España para conseguir la mejora de las condiciones en estos barrios consiste en desencadenar un proceso basado en intervenciones a pequeña escala incorporando el factor tiempo como ingrediente imprescindible para la construcción de la ciudad. A través de un cambio en las mentalidades tanto de gobiernos como de comunidades y garantizando la seguridad en la tenencia de la tierra, se trata de que los propios vecinos inviertan en la mejora de su barrio, confiando en el potencial de autoproducción de lo informal para conseguir la mejora progresiva de la ciudad.

Palabras Clave: barrios informales, acupuntura, tierra, participación, gentrificación. 
ABSTRACT: The informal settlements of Maputo, the capital of Mozambique, are home to eighty percent of the very poor, high-density urban population, living in precarious habitats. Like other African cities, Maputo faces the challenge of how to manage the anticipated growth of its urban population, while simultaneously improving the living conditions in the informal settlements, ensuring all its inhabitants have the right to the city, and avoiding socially and environmentally unsustainable urban growth. These neighbourhoods cannot be improved by large-scale urban planning operations or structural infrastructure projects alone. The proposal from Architecture Sans Frontières-Spain to enhance conditions in these neighbourhoods aims to trigger a process based on small-scale interventions where time is an essential ingredient for constructing the city. By changing the way communities and municipal governments think and guaranteeing land tenure, the population itself must invest in improving the neighbourhood, trusting in the potential of informality for self-production to gradually improve the city.

KEYWORDS: slums, acupuncture, land, participation, gentrification.

RESUM: Els barris informals de Maputo, capital de Moçambic, alberguen el $80 \%$ d'una població urbana molt pobre, amb altes densitats d'ocupació i alts nivells de precarietat de l'hàbitat. Maputo, com les altres ciutats africanes s'enfronta al repte de com fer front al creixement de la població urbana previst i simultàniament millorar les condicions de vida precàries en els assentaments informals garantint el dret a la ciutat per a tots els habitants sense generar lògiques de creixement urbà poc sostenibles des del punt de vista mediambiental i social. Aquests barris no poden ser millorats únicament a través de grans operacions de planejament urbà o d'intervenció en infraestructures estructurants. La proposta d'Arquitectura Sense Fronteres-Espanya per aconseguir la millora de les condicions en aquests barris consisteix en desencadenar un procés basat en intervencions a menuda escala incorporant el factor temps com a ingredient imprescindible per a la construcció de la ciutat. A través d'un canvi en les mentalitats tant de governs com de comunitats i garantint la seguretat en la tinença de la terra, es tracta que els propis veïns inverteixen en la millora del seu barri, confiant en el potencial d'autoproducció d'allò informal per aconseguir la millora progressiva de la ciutat.

PaRAules Clau: barris informals, acupuntura, terra, participació, gentrificació. 


\section{Los barrios informales de Maputo: problemáticas y contexto}

- i el 60\% de la población urbana subsahariana vive actualmente en slums (Ciudades africanas. Reto urbanístico y social, 2014), en Maputo, capital de Mozambique, este número asciende al 80\% (Jenkins, 2010) con una población urbana de las más pobres del mundo (Davis, 2006) (fig. 1).

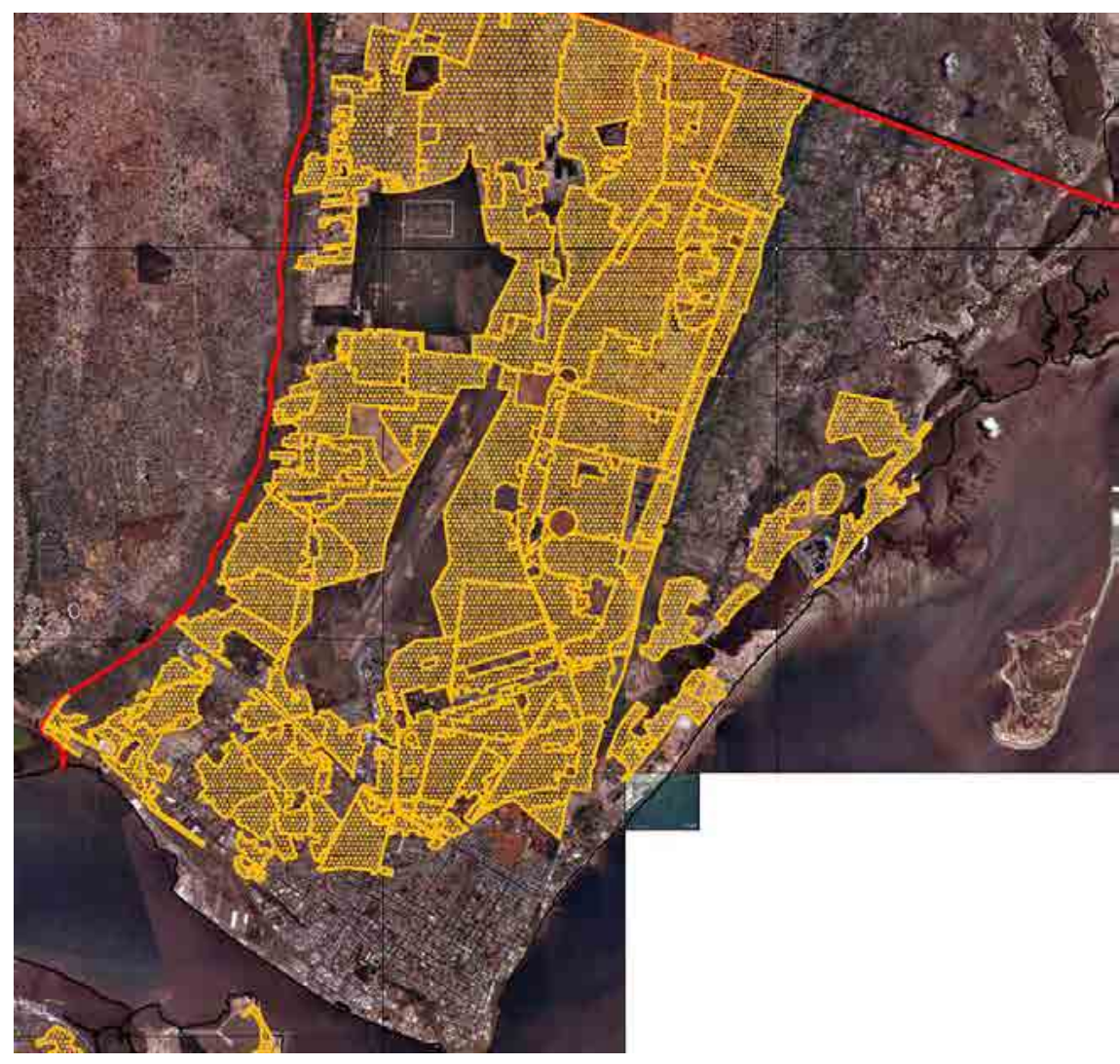

Figura 1. Asentamientos informales de Maputo resaltados en amarillo.

Fuente: Estrategia municipal de intervenção em assentamentos informais, CMM.

Los barrios informales de Maputo son herederos de dinámicas coloniales de segregación urbana y del éxodo rural masivo provocado por la guerra civil post independencia (1975-1992). En el periodo colonial Maputo era una ciudad de carácter dual, configurada para satisfacer las necesidades coloniales (Lopes, Oppenheimer, Sangreman Proença, Ribeiro, Cunha y Ferreira, 2007), compuesta por un centro urbano para la población colona planeado por la administración mientras que la periferia, insuficientemente infra-estructurada, 
era de carácter informal y auto-producida ${ }^{1}$ por la población local desplazada a la ciudad para servir como mano de obra temporal. Estos barrios informales, como en otras ciudades africanas se consideraban temporales (Davis, 2006); de hecho, la legislación colonial prohibía la construcción con materiales duraderos como el bloque de cemento en estos asentamientos.

Por el hecho de su crecimiento informal - a partir de subdivisiones sucesivas de parcelas de tierra para acoger a los inmigrantes rurales y refugiados de la guerra civil- los barrios informales más antiguos tienen una estructura de la tierra completamente desorganizada. Los más cercanos al centro alcanzan densidades relativamente elevadas 70-80 viv/Ha (CMM, 2008) con modelos habitacionales en planta baja, con infraestructuras deficientes y espacios públicos inexistentes — vías de acceso muy precarias de hasta 60 $\mathrm{cm}$ de ancho-, lo que genera inseguridad e insalubridad (inundaciones por suelos saturados, saneamiento precario, incendios, etc.) incentivadas por la precariedad de lo construido (fig. 2 y 3). En zonas más alejadas del centro urbano existen asentamientos informales más modernos con una parcelación ordenada y vías de acceso en retícula con menor densidad pero sin una programación suficiente de equipamientos públicos o infraestructuras básicas.

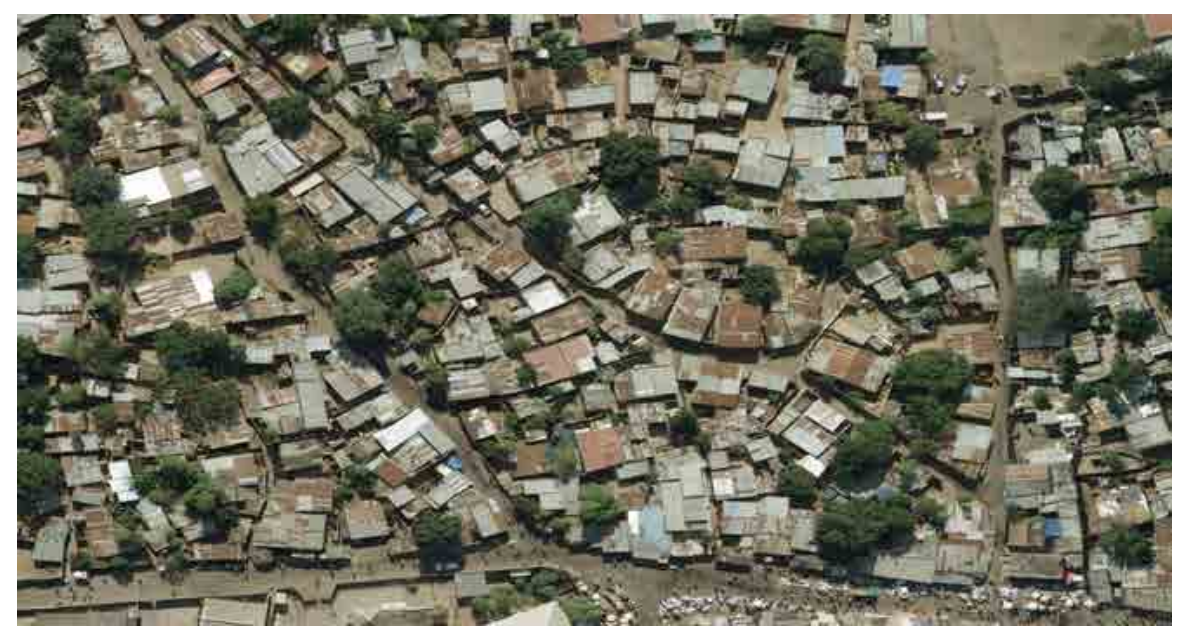

Figura 2. Ejemplos de tejido urbano de origen informal.

Fuente: ortofoto de Xipamanine cedida por el Conselho Municipal de Maputo.

1. El término «auto-producida» para designar la ciudad informal es empleado por Jorge y Melo (2014, p. 3). 


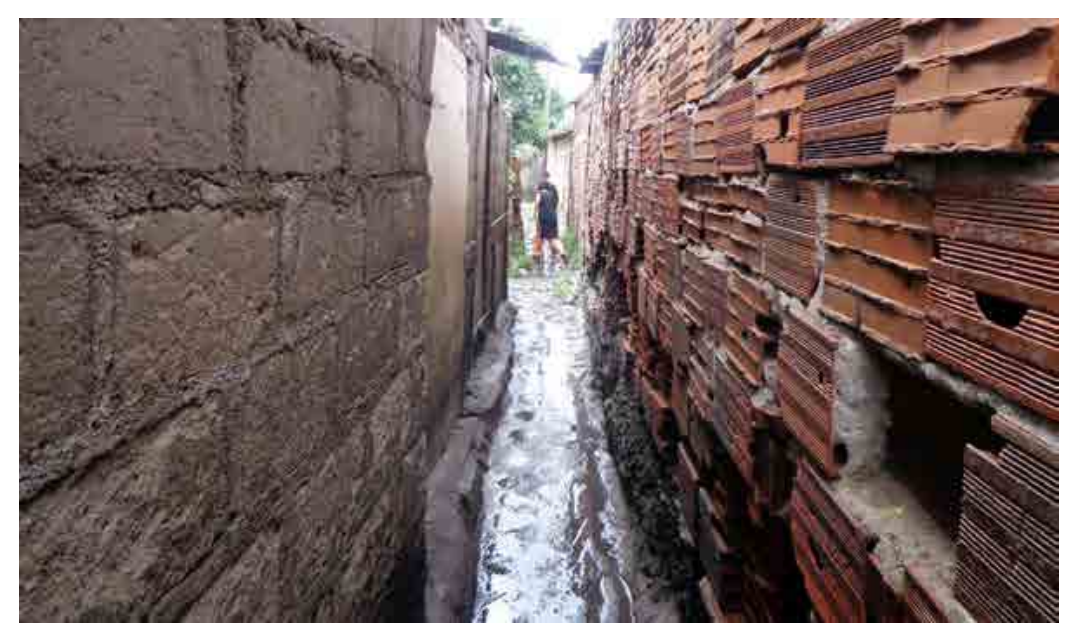

Figura 3. Vías de acceso en los barrios informales de Maputo. Fuente: fotografía Pablo Fernández.

En 1975, con la independencia de Mozambique, se nacionaliza la tierra como mecanismo de protección social frente a la especulación y para asegurar el derecho de todos sus habitantes a la tierra. La Ley de tierras (Decreto Lei 19/1997) establece el DUAT (Direito de Uso e Aproveitamento da Terra) como herramienta para la regularización de la tenencia de la tierra. El origen auto-producido de los barrios informales y las atribuciones informales de parcelas realizadas por los líderes locales contribuyen a que la ocupación de estos barrios sea anárquica y exista una completa informalidad de la tenencia de la tierra. En los barrios informales la mayoría de los habitantes no poseen DUAT, ya que no existe una parcelación oficial ni los niveles infraestructurales mínimos exigidos por ley para su atribución. Aunque frente a la ausencia de título formal se reconoce el derecho de uso de la tierra por ocupación de buena fe (ocupación de más de 10 años) como equivalente al título de DUAT, el hecho de que esta tenencia de la tierra no esté regularizada es fuente de frecuentes conflictos: a la hora de realizar transmisiones de tierra lo que afecta sobre todo a la población más vulnerable — la mujer puede verse desprovista de su casa en caso de herencia- o a la hora de establecer los límites entre parcelas colindantes o entre el espacio parcelado y el espacio público, ya que no existen límites reconocidos legalmente. 
Esta desregularización de la tenencia de la tierra es fuente de inseguridad y limita las inversiones de los propios vecinos para la mejora de las viviendas, ya que en cierta medida la concepción de que estos barrios son temporales sigue presente en el ideario colectivo. De hecho debido a la inseguridad en la tenencia de la tierra, la precariedad de las infraestructuras básicas y las altas densidades de estos barrios no es poco frecuente que los vecinos prefieran, en caso de intervención de mejora urbana en el barrio, ser reasentados en barrios periféricos. No obstante, si bien es cierto que algunos habitantes desplazados prefieren un modo de vida más rural y eligen el reasentamiento, no existen alternativas para aquellos habitantes que quieran tener un modo de vida más urbano y continuar viviendo en áreas próximas al centro (Jorge et al., 2014).

\section{Expulsión de la población más vulnerable hacia la periferia}

Debido a la localización estratégica de estos barrios informales comienzan a darse procesos especulativos en los que inversores compran en un mercado informal - la tierra es pública, legalmente no se puede comprar ni venderlos terrenos a familias en condiciones muy desfavorables generando una lógica de expansión urbana basada en la expulsión sistemática del más pobre a la periferia. Estas transacciones de solares se hacen de manera informal con cada propietario, negociando individualmente los precios de indemnización o compra de las viviendas sin tener en cuenta en la mayoría de los casos el valor intangible de las viviendas que deriva, entre otros factores, de su proximidad al centro (Jorge et al., 2014). En muchos casos las familias no tienen mecanismos para evaluar cuáles son los gastos añadidos de su deslocalización a la periferia y estas operaciones de compra-venta que en un principio parecen ventajosas agravan la situación económica de la familia, ya que en la periferia el acceso a las infraestructuras básicas es más difícil (escuelas, hospitales, etc.) y las principales fuentes de rendimiento de estas familias se encuentran en el centro de la ciudad, ya sea en el sector formal o en el informal.

Incluso en caso de operaciones de mejora urbana se replica este proceso de expulsión en condiciones injustas de la población más vulnerable a la periferia. La normativa municipal establece unos baremos de indemnización por las infraestructuras de las familias afectadas por una operación de reasentamiento y estipula que se debe asegurar a esas familias un terreno con 
infraestructuras y una casa o medios económicos para construirla. Ley que en muchos casos no se cumple porque el planeamiento urbano se deja en manos de privados y un municipio con escasos recursos se ve incapaz de asegurar el cumplimiento de la ley.

Se perpetúa así un proceso de elitización del centro urbano en el que el tejido informal con altas densidades da paso a áreas residenciales de baja densidad. Es el caso de Polana Caniço A y B donde las urbanizaciones de lujo de Sommerschield están comiendo terreno al tejido residencial de los barrios informales (fig. 4). Esta disputa entre las necesidades de espacio de las poblaciones suburbanas y de las élites de las ciudades provoca la deslocalización hacia la periferia de las familias con menos recursos, proceso que se ve facilitado por el hecho de que la mayoría de los habitantes de los barrios suburbanos no poseen documentos legales de ocupación (Raposo y Salvador, 2007). Este proceso no sólo genera una lógica de expulsión de la población con menos recursos, si no que genera una ciudad cada vez menos densa tanto en el centro como en la periferia, comprometiendo así el desarrollo sostenible de la ciudad.

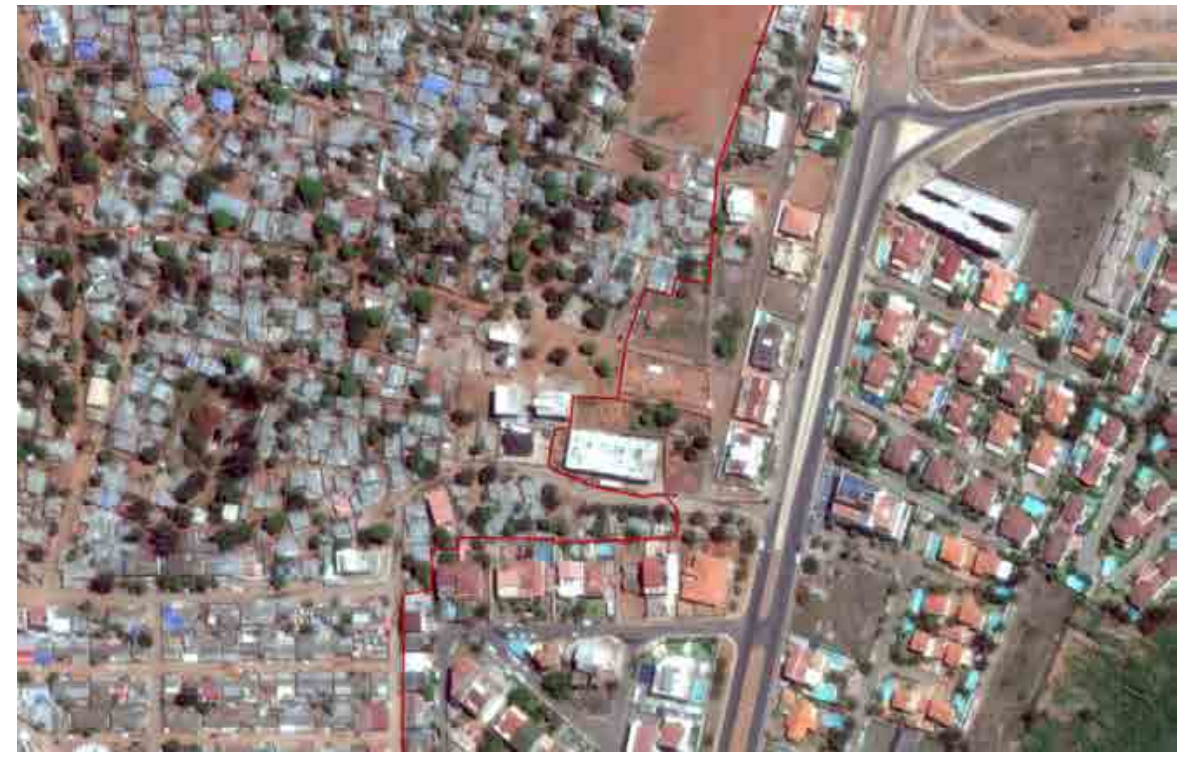

Figura 4. Fotografía aérea en la que se ha evidenciado el límite entre el barrio informal (Polana Caniço $\mathrm{A}$ a la izquierda) y el barrio residencial de clase alta (Sommerschield a la derecha). Fuente: elaboración propia a partir de Google Maps. 


\section{El agravante del crecimiento urbano}

Este contexto de precariedad del hábitat, de expulsión sistemática de los habitantes de los asentamientos informales a la periferia de la ciudad y de crecimiento urbano en baja densidad se ve agravado por las previsiones de crecimiento urbano para este siglo. Según las estadísticas, África es el continente con las tasas de crecimiento urbano más altas $(4,5 \%)$ y se prevé que en apenas 30 años el número de sus habitantes sea dos veces mayor que el actual (UN-Hábitat, 2014). En este contexto, planificar el crecimiento urbano es prioritario para los municipios africanos. Maputo, que cuenta actualmente con 1,2 millones de habitantes (United Nations, 2016), la lentitud del proceso de descentralización en Mozambique, los enfrentamientos armados en el campo, la sequía y el propio crecimiento natural de la actual población urbana — principal motor de crecimiento urbano en Maputo en la actualidad (Jenkins, 2010) — crecerá a una tasa de 3,2\% anual entre 2016 y 2030 (United Nations, 2016).

Maputo no tiene medios para anticiparse a este crecimiento de la población urbana. Las instituciones para garantizar el acceso a la vivienda creadas tras la independencia —el Fundo de Fomento à Habitação y APIE² — están obsoletas. La falta de vivienda social o de mecanismos de acceso a la vivienda incluso para la clase media es flagrante: recientemente se anunciaba en medios de comunicación nacionales la construcción de 5000 viviendas supuestamente dirigidas para la clase media (Chambisso, 2017). El artículo anunciaba casas para rentas medias por 70000 uSD a pagar en mensualidades de 38500 MZN (equivalentes a 628 USD) cuando el salario mínimo ronda los 6000 MZN (o 98 USD) (Wageindicator, 2017).

El centro urbano está colmatado y acaparado por las élites. El planeamiento urbano ${ }^{3}$ se deja en manos de privados: la mayor parte de las construc-

2. ApIE: Administración de la Propiedad Inmobiliaria del Estado. Institución para administrar las viviendas que fueron expropiadas a los portugueses y la segunda vivienda considerada tras la independencia. Actualmente APIE sigue siendo propietario de algunas casas en su gran mayoría muy precarias que alquila a precios subsidiados ya que tras la liberalización del mercado inmobiliario en 1991 los propietarios de casas de APIE las compraron.

3. Se hace alusión aquí a operaciones de parcelación realizadas por privados en grandes urbanizaciones como es por ejemplo el proyecto Intaka con 500 viviendas en una macro-urbanización cerrada en la periferia del área metropolitana de Maputo. 
ciones formales de nueva vivienda son para una clase media/alta que busca alojarse en la periferia en urbanizaciones cerradas, en promociones de «lujo». La clase media se instala en parcelas cada vez más alejadas del centro con la autoconstrucción como mecanismo de producción del hábitat, ya que el acceso al crédito es muy reducido y la propiedad de la vivienda es un mecanismo de seguridad social en un contexto de gran informalidad de la economía — según António y Margarida (2006) el sector informal representa el $90 \%$ de la economía mozambiqueña.

Las clases más bajas se instalan en nuevas áreas periféricas con bajas densidades de población generando una ciudad poco densa y dispersa, sin infraestructuras básicas, en la que cada vez los problemas de movilidad son mayores, o en los barrios informales más cercanos al centro en terrenos inseguros o en áreas con densidades ya muy elevadas y condiciones de vida precarias.

El incremento previsto de la población urbana provocará inevitablemente un aumento de la población en barrios informales, ya sea en nuevas áreas informales en la periferia o a través de la densificación y precarización de los asentamientos informales existentes. Inevitablemente generará más informalidad y desigualdad.

\section{Intervenciones de mejoramiento barrial}

Para garantizar el derecho a la ciudad de los habitantes es urgente prever estrategias para que este aumento de la población no derive en un empeoramiento drástico de las condiciones de los asentamientos informales debido a la densificación de áreas no planificadas o en una extensión urbana sin freno generando una ciudad poco compacta - y por ende menos sostenible (Swilling, 2016) - en la que el acceso a las infraestructuras básicas y las alternativas de movilidad urbana sean poco viables.

El Municipio de Maputo ha identificado el mejoramiento de los barrios informales como un elemento prioritario de su agenda. Con el apoyo de financiaciones multimillonarias extranjeras se han puesto en marcha programas como el PROMAPUTO (Programa financiando por el Banco Mundial para el desarrollo de Maputo) entre cuyos objetivos se encuentra la mejora de los barrios informales. 
Estas operaciones llevadas a cabo por el Municipio en los últimos años incluyen la elaboración de Planes Parciales de Urbanización (PPU) ${ }^{4}$ o intervenciones prioritarias en infraestructuras estructurantes de los barrios. Incluso si se trata de una herramienta necesaria para definir la estructura urbana de los barrios, la elaboración de PPU genera grandes expectativas en una población que no entiende la necesidad de herramientas de planeamiento urbano que no presentan mejoras tangibles a corto plazo. Además, tanto en el caso de la elaboración de PPU como en las intervenciones en infraestructuras prioritarias, no se interviene en la restructuración de la tenencia de la tierra en las áreas en las que ésta es desordenada dejando grandes «bolsas» informales con un planeamiento por definir a espera de que intervenga el sector privado.

En estos barrios periféricos se da la paradoja de que la elaboración de proyectos y propuestas de intervención como los PPU paraliza el desarrollo y el dinamismo natural de estos barrios. Ya sea por las actitudes especulativas de agentes puntuales o por el miedo de sus habitantes a invertir en el mejoramiento de sus viviendas cuando el barrio está en un proceso de recalificación que puede significar su expulsión del barrio, se perpetúa la inseguridad de la ocupación reforzando la precariedad. Ejemplo de ello es la transformación paulatina del territorio llevada a cabo por inversores privados que adquieren parcelas a lo largo de las calles principales ya urbanizadas, destruyendo el tejido residencial preexistente y dejando estos solares en stand-by, usándolos como aparcamientos o naves de almacenamiento a espera de que se complete la regularización del barrio, obtener un DUAT que asegure su posición y construir. Ver la figura 5 que muestra las transformaciones en los solares que limitan con una calle principal en uno de los barrios informales más antiguos de Maputo.

4. $\quad$ En Mozambique el Plan Parcial de Urbanización (PPU) «establece la estructura y califica el suelo parcialmente, teniendo en consideración el equilibrio entre los diversos usos y funciones urbanas, define las redes de transporte, comunicaciones, energía y saneamiento y los equipamientos sociales» (RdM, 2008) a nivel estructurante de los barrios pero no indica alineaciones, ni parcelación, ni usos pormenorizados del suelo. 


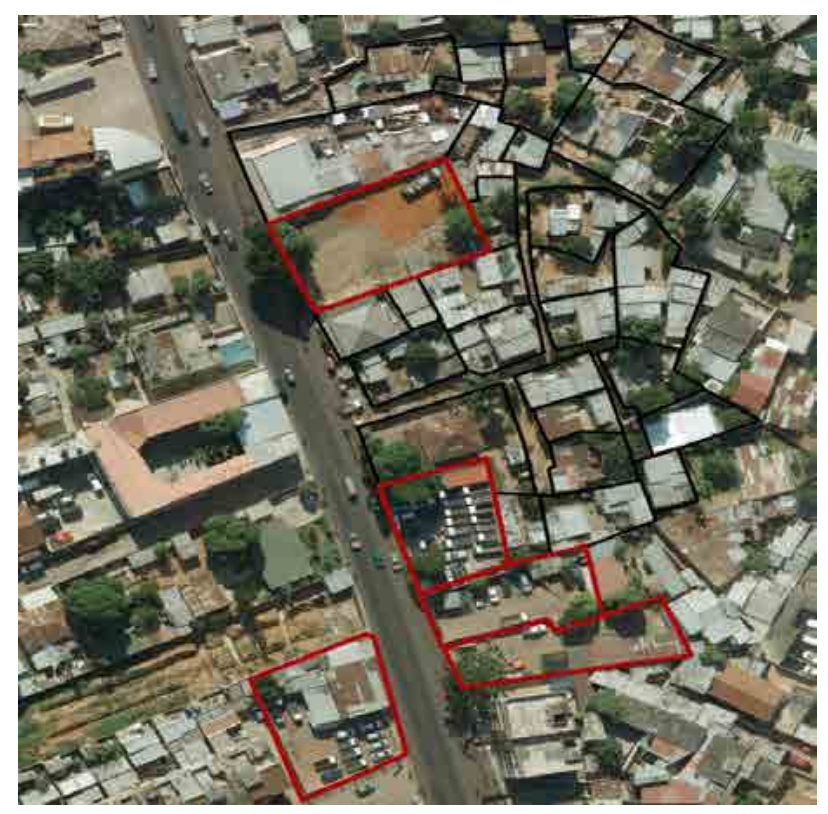

Figura 5. Imagen aérea de la calle Irmãos Roby (Xipamanine) en la que se han evidenciado las transformaciones en la estructura parcelaria. Fuente: elaboración propia a partir de Google Maps.

\section{Acupuntura urbana como alternativa}

De manera complementaria a la elaboración de herramientas urbanísticas que nortean el desarrollo de un barrio y de identificar y construir las infraestructuras prioritarias — para conectar este barrio con el resto de la ciudades necesario llevar a cabo intervenciones a menor escala, a nivel de barrio. Pensar en el problema de los asentamientos informales a nivel de ciudad es imprescindible pero es importante desarrollar también soluciones a escala de barrio para la mejora in situ que van más allá de las infraestructuras estructurantes. En el caso de Maputo esto sigue siendo un desafío para el Municipio debido a la complejidad de algunos de los barrios informales de la ciudad. Y sin embargo la mejora in situ de los barrios a través de intervenciones de menor escala, incluso puntuales, mediante operaciones de acupuntura urbana es la única alternativa sostenible social y económicamente; no se puede pensar en el mejoramiento de los barrios informales a partir de grandes y costosas operaciones que suponen un borrón y cuenta nueva en la estructura del barrio. Operaciones a pequeña escala que respeten el tejido — físico y social— 
existente en los barrios informales entendiendo, como señala Lerner (2003), estas operaciones de acupuntura urbana como catalizador del cambio más que como un cambio en sí mismas.

El objetivo de las operaciones de mejoramiento barrial es acabar con las 5 privaciones básicas de los barrios informales (UN-Hábitat 2003) —inseguridad de la tenencia de la tierra y derechos sobre la vivienda; acceso inadecuado a una fuente de agua segura; acceso inadecuado a saneamiento y otras infraestructuras; baja calidad estructural de la vivienda; hacinamiento-y de una forma más amplia asegurar el derecho a la ciudad de los habitantes de los barrios informales. Este derecho a la ciudad incluye el acceso a las infraestructuras básicas, a una red de espacios libres públicos de calidad y a una tenencia segura de la tierra, pero es también el derecho al acceso a las oportunidades que da la ciudad, a los centros económicos de producción y centros de trabajo, a las instituciones públicas y equipamientos sociales (hospitales, colegios, etc.) de una forma no discriminatoria lo que, debido a los crecientes problemas que plantea la movilidad urbana, cada vez es más complicado. Incluso, tomando la definición de Lefebvre (1968) sobre el derecho a la ciudad, éste implica también el derecho de los ciudadanos a participar en su ordenación y modificación, el derecho político de definir la ciudad. Según esta definición el derecho a la ciudad es el derecho colectivo para dar forma a los procesos de configuración de la ciudad.

Se habla mucho de participación y está ampliamente aceptado que es un factor importante del proceso de planeamiento urbano. De hecho, según la Ley de Ordenamiento del Territorio (RdM, 2008), la participación ciudadana es obligatoria para la aprobación de los planos y se traduce en sesiones de consulta pública y espacios para realizar alegaciones. No obstante, esta participación en muchas ocasiones no es verdadera - los conceptos y las formas de presentar la información de los planos urbanísticos son inaccesibles para la mayor parte de la población-. Incluso cuando un proceso de planeamiento urbano consigue movilizar a una buena participación de la población en el diseño es necesario ir más allá y planear contando con la participación a posteriori, de forma dilatada en el tiempo. Esto es importante sobre todo en un contexto de informalidad donde hay que movilizar la capacidad de auto-producción de los barrios informales. 


\section{Experiencia en Chamanculo C}

Chamanculo $\mathrm{C}$ es uno de los barrios informales más antiguos y densos de la ciudad, relativamente bien situado, cerca del centro. Carece de una estructura clara, ya que ha ido creciendo de forma informal no planificada a través de ocupaciones y subdivisiones de parcelas sucesivas debidas al éxodo rural o al crecimiento natural (fig. 6). Como en la mayoría de los barrios vecinos, las ocupaciones de espacio público han sido una dinámica habitual durante años a medida que ha ido aumentando la población. La degradación paulatina de los espacios públicos es una dinámica que todavía sigue existiendo y las parcelas son pequeñas y las familias numerosas. Según los testimonios de los vecinos del barrio, muchas de las calles de estos barrios informales - que ahora apenas tienen 1,5 metros de sección - en la era colonial eran amplias y permitían el paso de camiones. De hecho, en el plazo de 3 años — entre la fecha de la ortofoto y el levantamiento realizado en Chamanculo $\mathrm{C}$ - había desaparecido un callejón, ocupado por parcelas privadas.

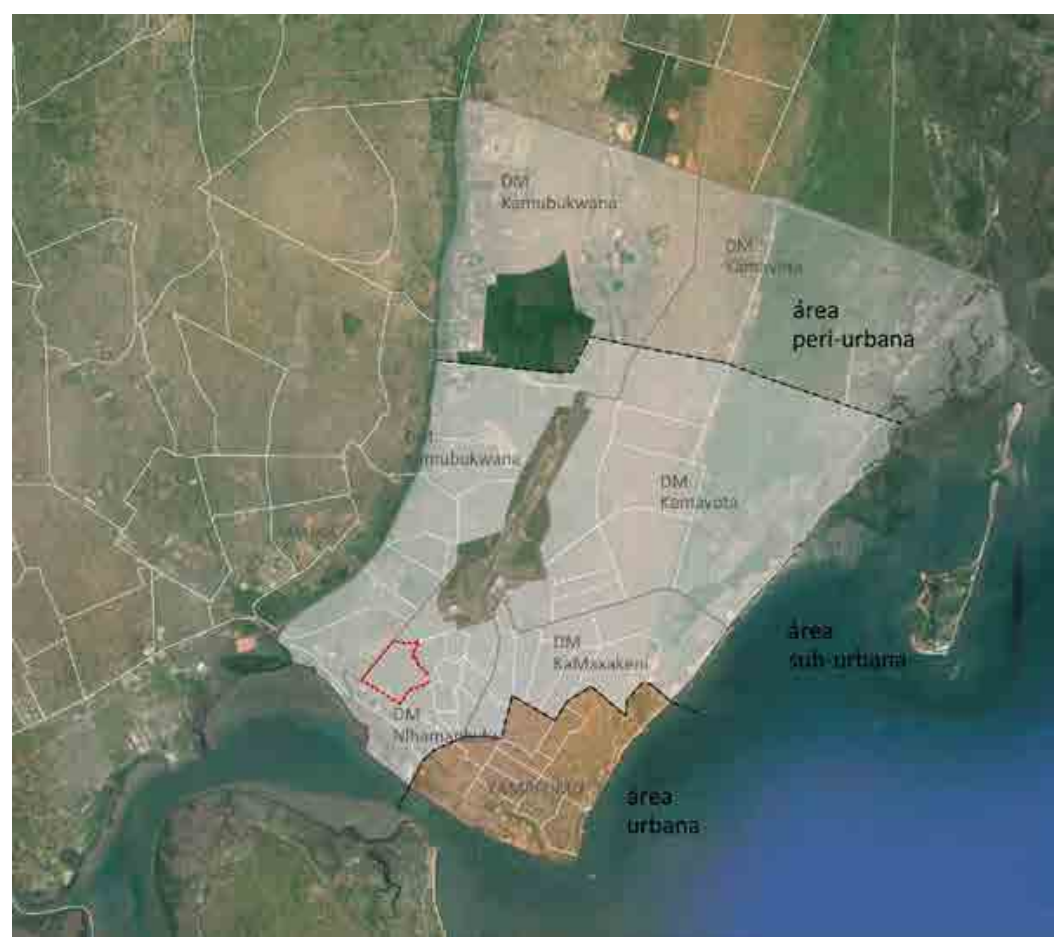

Figura 6. Localización de Chamanculo C (resaltado en rojo) y división entre la ciudad formal (fondo naranja) y ciudad informal (fondo gris). Fuente: elaboración propia a partir de Google Maps. 
Por su localización y características, Chamanculo C es uno de los barrios que el Municipio de Maputo ha escogido como piloto para establecer una metodología de recualificación de los asentamientos informales. Esta metodología incluye el mapeo del barrio y diagnóstico, la elaboración del PPU y la definición y realización de intervenciones prioritarias entre las cuales destacan la pavimentación de la arteria principal y la construcción de una acequia de drenaje de aguas pluviales. Durante el desarrollo se involucró a la población en procesos de sensibilización y de consulta pública —el que estipula la ley para la elaboración de los planos (fig. 7).
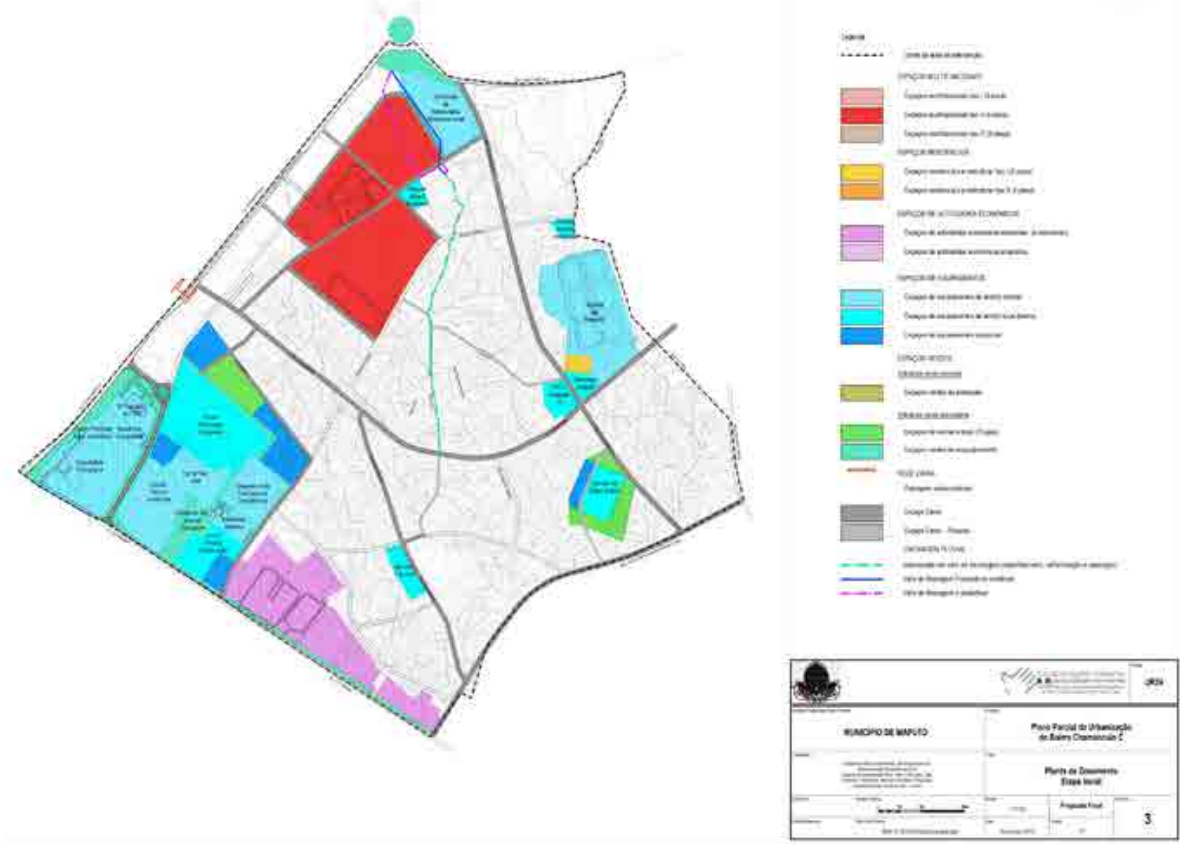

Figura 7. Plano de usos del suelo e intervenciones prioritarias. Extracto del Plano Parcial para Chamanculo C. Fuente: CMM.

Arquitectura Sin Fronteras-España comenzó a trabajar en Chamanculo C en 2015 aprovechando toda la base documental y de diagnóstico existente con el objetivo de regularizar la tenencia de la tierra a través de la atribución de DUAT. Como se ha visto anteriormente, la seguridad en la tenencia de la tierra es imprescindible para que pueda generarse un proceso de mejora urbana. $\mathrm{La}$ normativa municipal establece dos condiciones básicas que deben cumplirse 
para que la atribución del DUAT sea posible. El área que se pretende regularizar debe tener un planeamiento urbano aprobado (un PPU o un Plano de Pormenor) y deben existir unas condiciones mínimas de acceso a las parcelas. Como en Chamanculo C el Municipio ya había desarrollado el PPU, la condición en la que se debía trabajar para la atribución del DUAT era únicamente la mejora de los espacios públicos y la accesibilidad.

En una primera etapa se seleccionaron 5 manzanas del barrio para realizar una experiencia piloto en la que ensayar una intervención de ampliación de la red viaria en 3 calles interiores de estas manzanas en un tramo de 300 metros de largo. Para ello era necesario reducir el espacio de las parcelas con un doble objetivo - mejorar la accesibilidad, la calidad del espacio público, la seguridad y salubridad - e iniciar un proceso de reordenación urbanística, partiendo del límite entre lo público y lo privado y permitir así la concesión de títulos de DUAT (fig. 8).

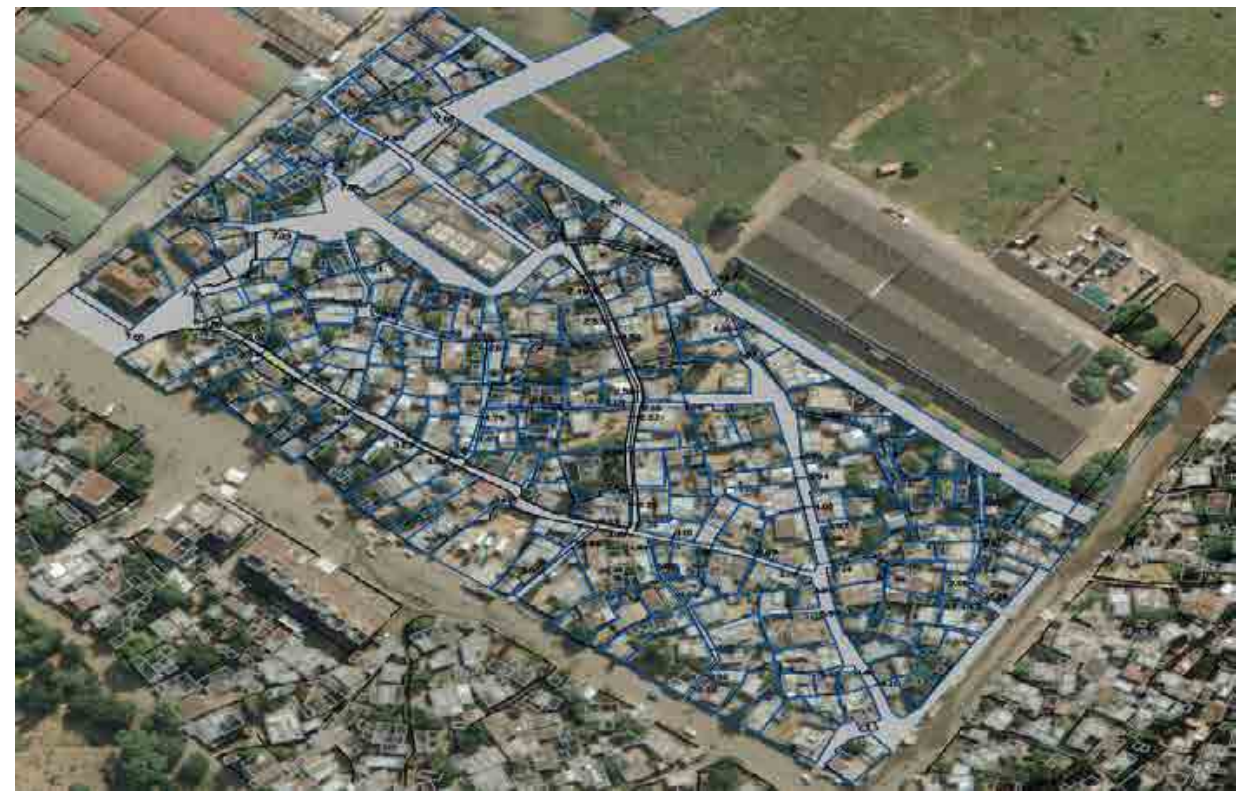

Figura 8. Nueva parcelación y estructura viaria en las manzanas del área piloto. Fuente: Arquitectura Sin Fronteras - España.

En este contexto, la sensibilización de la comunidad no sólo sobre la importancia del título de DUAT - para que los vecinos entiendan cuáles son los beneficios de una tenencia de la tierra regularizada - , sino también sobre la importancia de los espacios públicos son imprescindibles. De hecho, esta 
intervención en las tres calles forma parte de un proyecto más amplio en el que se incluyen actividades de sensibilización sobre la importancia del derecho a la tierra, de resolución de conflictos legales derivados de la tenencia insegura en el barrio, de sensibilización sobre la importancia de los espacios públicos y de diseño y rehabilitación participativos de 3 espacios públicos en el barrio.

El Municipio de Maputo fue el principal socio local y su participación en el proyecto se aseguró a través del acompañamiento del proceso por un técnico del área de urbanismo para conseguir que la metodología sea transferida al propio Municipio y que sea éste quien potencie y lidere iniciativas similares en el futuro. Otras instituciones involucradas en el proyecto incluyen al Colegio de Abogados, para cuestiones de conflictos legales relacionados con la tenencia de la tierra, y organizaciones comunitarias de base del barrio que fueron formadas para apoyar en las actividades de sensibilización del proyecto y para servir como puntos focales para informar a la población sobre el derecho a la tierra en el futuro.

A lo largo del proceso se realizaron múltiples reuniones comunitarias con todo el barrio para compartir la metodología y escoger el área de la experiencia piloto. Sin embargo, un mal entendimiento por parte de la población de los resultados esperados del proyecto previo de recualificación del barrio iniciado por el ayuntamiento (citado más arriba) había generado — pese a las campañas de sensibilización realizadas - altas expectativas. Estas expectativas no consiguieron cumplirse, lo que había generado desconfianza entre los habitantes. Esta desconfianza se hizo visible en las primeras reuniones con la comunidad. El apoyo de los líderes comunitarios y jefes de manzana como movilizadores de la comunidad y para el seguimiento de todo el proceso fue imprescindible.

La primera etapa consistió en el levantamiento de los límites actuales de las parcelas visitando todas las casas y estableciendo junto a los vecinos los límites consensuados entre parcelas colindantes contando con la mediación de los líderes comunitarios. Es importante resaltar que, como parte de este proceso, se consiguió empoderar también a estos líderes locales que son el vínculo entre la población y el municipio y que tienen la labor de informar, transmitir preocupaciones y controlar el respeto de las normas urbanísticas, 
como limitar los acaparamientos de espacios públicos, la construcción de letrinas y pozos de drenaje en el espacio público, que son prácticas habituales. A través del mapeo se dotó a los líderes de herramientas para conocer las casas de sus manzanas, los límites entre lo público y lo privado y buenas prácticas de ocupación.

Posteriormente se inició un proceso de encuentros con todos los vecinos de las manzanas seleccionadas para escoger las calles a ampliar y, finalmente, se realizaron reuniones familia por familia con las 30 familias afectadas por las intervenciones necesarias, una vez más, con el apoyo de los líderes comunitarios. Después de 3 meses de conversaciones y presencia constante en el barrio se consiguió que los vecinos cedieran espacio de sus parcelas para la ampliación de las vías de acceso, anteponiendo, así, el beneficio colectivo al interés particular (fig. 9a y 9b). La cesión de estos espacios se realizó sin derecho a indemnización por el espacio cedido pero con la reconstrucción de las infraestructuras afectadas (muros, fosas sépticas, pozos de drenaje, quioscos de venta) y posibilita la posterior atribución de títulos de tierra. Sorprendentemente, las familias con parcelas de menores dimensiones son las menos reticentes a ceder espacio para la ampliación de las calles. Esto probablemente deriva de la mayor sensación de inseguridad en el caso de estas familias para las que la consolidación del barrio es más prioritaria.

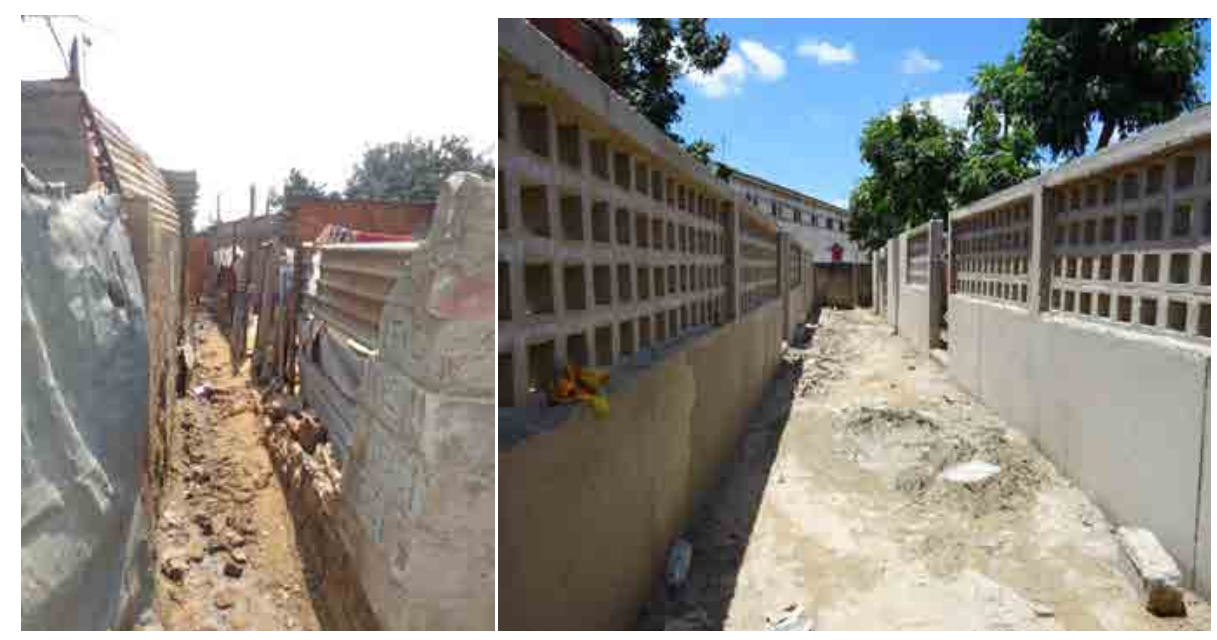

Figuras $9 a$ y $9 b$. Imágenes del antes (a) y del después (b) de la intervención en Chamanculo $C$.

Fuente: fotografía de Silvia Scholl (ASF-E). 
Para minimizar el impacto social, evitando reasentamientos, y maximizar la visibilidad de la intervención con los fondos disponibles, algunas de las casas en las calles escogidas no se han modificado. Parte de las casas principales no respetan la alineación y sobresalen respecto a la línea establecida por los nuevos muros, pero se ha conseguido el compromiso de las familias de respetar la nueva alineación a la hora de reconstruirlas, lo que teniendo en cuenta la precariedad de los materiales de construcción y la poca consolidación de lo construido ocurrirá a corto o medio plazo. En algunos de los casos los propios vecinos ya han iniciado la construcción de infraestructuras por sus propios medios siguiendo la nueva alineación.

Con un presupuesto relativamente reducido para las obras — de 30.000 euros - se realizó la reconstrucción de 300 metros lineales de muros de cierre de parcela y paredes de casas afectadas, 6 fosas sépticas, 6 pozos de drenaje, 9 cuartos de baño y 1 quiosco de venta, contando con la participación de los propios vecinos en la construcción. A este valor hay que sumar, no obstante, el coste de la sensibilización y acompañamiento de la población por técnicos sociales que, en esta primera fase, fueron elevados debido a la poca receptividad inicial de la población derivada de las altas expectativas creadas por el proyecto anterior. En las fases posteriores este proceso de negociación será más fácil y más rápido. En total, alrededor de 300 familias que utilizan estas calles para acceder a sus casas se han visto beneficiadas por la ampliación de las mismas; a este número hay que añadir a los vecinos de todo el barrio que han visto las posibilidades de mejora y potencialidades de Chamanculo $\mathrm{C}$.

La principal ventaja de este tipo de operación es que, al ser una operación de acupuntura urbana de relativamente bajo coste, puede ser replicada por el Municipio sin depender de grandes financiaciones externas e incluso por los propios vecinos, pudiendo ser una metodología válida para la mejora urbana de todos los asentamientos informales de la ciudad.

Tras la ampliación de las vías de acceso se puede proceder a la petición de atribución de títulos de DUAT. El desafío en esta fase consistirá en proponer una parcelación regularizada respecto a la parcelación existente de tal forma que, aunque pueda haber algunas diferencias entre las parcelas actuales y las parcelas regularizadas, se re-estructure ligeramente la forma tan desordenada de las parcelas para permitir cambios y mejoras en los modelos habitacionales 
en el futuro pero respetando la estructura y la riqueza del asentamiento informal. Una vez más se deberá contar con la participación de la población en el diseño de la nueva parcelación y del nuevo modelo de ocupación del barrio. Este modelo de ocupación del barrio deberá plantear un proceso de densificación paulatina y probablemente de modificación de las tipologías de vivienda (construcción en 2 plantas, por ejemplo), necesario si se quiere conseguir una densidad elevada con una proporción adecuada de espacios públicos y equipamientos suficientes en el barrio.

Existe, no obstante, un peligro en este proceso y es que, al regularizar la tenencia de la tierra, se facilitan los procesos de gentrificación, ya que los traspasos de tierra son más seguros para los inversores si existe título de DUAT. Por ello es bueno que sea un proceso paulatino, en el que la mejora de las condiciones de vida de los habitantes y sus inversiones en las casas estén estrechamente ligadas a la mejora de las condiciones del barrio. No obstante, es necesario, a lo largo del proceso, empoderar a los habitantes para que la visión a largo plazo se imponga sobre la tentación del beneficio a corto plazo ofrecido por inversores privados en el ámbito de la especulación.

\section{Conclusiones: cambio de mentalidad y ciudad progresiva}

Lo que en un primer momento parecía imposible tanto a ojos del Municipio como de los propios líderes comunitarios ( «En Chamanculo no se puede conseguir que nos pongamos de acuerdo» decían los vecinos en los primeros encuentros comunitarios) ha derivado, en un año, en la ampliación de 3 calles con hasta 3 metros de sección y en peticiones de vecinos, reticentes a ceder parte de sus terrenos en un primer momento, para que la intervención se realice en sus calles.

Con este ejemplo se ha conseguido demostrar que es posible revertir una dinámica de empeoramiento progresivo de los espacios públicos, modificando la percepción que los vecinos tienen de su barrio e iniciando un cambio de mentalidad. Esta operación ha conseguido revertir una tendencia de ocupación del espacio público y llevar - todavía a pequeña escala y a modo de intervención piloto - la evolución natural de los asentamientos informales hacia la reivindicación de lo público. La participación y el poder catalítico 
de las intervenciones físicas generan este cambio de mentalidad que permite desencadenar, a su vez, un proceso de mejoramiento barrial basado en la capacidad de autoproducción de los barrios informales y que tiene en cuenta el factor tiempo, imprescindible en la configuración de la ciudad.

Este cambio de mentalidad se puede conseguir no sólo a través de intervenciones físicas sino también, por ejemplo, a través de incentivos de actividades generadoras de recursos que desencadenan una mayor inversión de los vecinos en la mejoría de su barrio (Hoelzel, 2013). Teniendo en cuenta la magnitud del desafío de la urbanización y de los barrios informales - en África sobre todo pero también en otras partes del mundo - no hay otra alternativa. No existen fondos suficientes para mejorar los barrios precarios si no se involucra en el proceso a la economía y la capacidad de auto-producción propias de los habitantes de los barrios informales.

El planeamiento urbano — por definición — tiene como objetivo regularizar y estructurar, pero tiene que asumir la incertidumbre asociada a los tiempos propios del desarrollo urbano y no presentarse como una intervención cerrada y acabada de diseño. El urbanismo es un proceso y tiene que incorporar el factor tiempo y la participación y la capacidad de crear de sus habitantes como herramientas imprescindibles para la construcción de la ciudad. En esta línea tiene sentido retomar la reflexión de Alexander (1965) sobre la importancia de la «pátina de la vida» y de las ciudades como un proceso complejo y vivo, aun tratándose de un contexto muy diferente. Porque, como bien dice Lerner (2003), acupuntura urbana es que se genere una chispa. 


\section{Referencias}

África Vive (Mayo 2014). Ciudades Africanas: Reto urbanístico y social. Mesa redonda en el marco de «África Vive». Instituto Cervantes, Madrid, España.

Alexander, C. (1965). La ciudad no es un árbol. (1968) Buenos Aires: Lata Méndez Mosquera y Jorge Grisetti.

António A. da Silva, F. y Margarida, P. (2006). Impacto da Economia Informal na Protecção Social, Pobreza e Exclusão: A Dimensão Oculta da Informalidade em Moçambique. Maputo, Mozambique: Centro de Estudos Africanos e Cruceiro do Sul.

Chambisso, C. (2017/04/11). «Maputo terá mais um projecto de cinco mil casas». O país. Recuperado el 10/04/2017 de http://opais. sapo.mz/index.php/economia/38-economia/44321-maputo-tera-mais-um-projecto-de-cinco-mil-casas.html

Conselho Municipal de Maputo (CMm) (2008). Plano de Estrutura do Município de Maputo (PEUMM). Maputo, Mozambique.

DAVIS, M. (2006). Planet of Slums. (Paperback edition 2017.) London: Verso.

Hoelzel, F. (2013) Upgrade Your Slum. [video] Hamburg: TEDx Hamburg. City 2.0

Jenkins, P. (2010). Relatório de Contexto. «Programa de pesquisa compreender o espaço do lar na cidade africana de Maputo». Workshop «home space» compreender o «espaço do lar» na cidade africana». Maputo, Mozambique.

Jorge, S. Y Melo, V. (2014). «Processos e Dinâmicas de Intervenção no Espaço Peri-urbano: O caso de Maputo». Cadernos de Estudos Africanos [Online], 27 | 2014, publicado online el dia 17 de junio de 2014 en http://cea.revues.org/1488; DOI: 10.4000/cea.1488

Lerner, J. (2003). Acupuntura urbana. (5a edición 2011) Rio de Janeiro: Editora Record.

Lopes, C. M., Oppenheimer, J., Sangreman Proença, C., Ribeiro, M., Cunha, N. y Ferreira, M. (2007). «Economia de Luanda e Maputo, Olhares cruzados». En Oppenheimer, J., y Raposo, I. (Coord.), Subúrbios Luanda e Maputo (pp. 65-85). Lisboa: Edições Colibri.

Raposo, I., y SAlvador, C. (2007). «Há diferença: Ali é cidade, aqui é subúrbio: Urbanidade dos bairros, tipos e estratégias de habitação em Luanda e Maputo». En Oppenheimer, Jochen y Raposo, Isabel (Coord.), Subúrbios Luanda e Maputo (pp. 105-138). Lisboa: Edições Colibri. 
República de MoçambiQue (1997). Lei de Tierras, Decreto Lei no 19/1997.

República de Moçambique (2008). Lei de Ordenamento do Território, Decreto-Lei n ${ }^{\circ} 23 / 200 \mathrm{~m} 8$.

Swilling, M. (2016). «The curse of urban sprawl: how cities grow, and why this has to change», Cities. Recuperado el 09/11/2017 de: https:// www.theguardian.com/cities

United Nations (2016). The world's cities in 2016. Data booklet. Recuperado el 28/04/2017 de: http://www.un.org/en/development/desa/population/publications/pdf/urbanization/the_worlds_cities_in_2016_ data_booklet.pdf

United Nations Human Settlements Programme (UN-Habitat) (2003). The Challenge of Slums. Global report on urban settlements. London: Earthscan Publications Ltd.

United Nations Human Settlements Programme (UN-Habitat) (2014). The state of African cities 2014. Re-imagining sustainable urban transitions. Recuperado de http://unhabitat.org/the-state-of-africancities-2014

Wage Indicator (2017). Salário Mínimo em Moçambique, a partir de 0104-2017 a 31-03-2018. Recuperado el 29/04/2017 de http://www. meusalario.com/inicio 